\title{
TALENT ACQUISITION: A CASE OF INNOVATION AND CHANGE IN CAMPUS HIRING
}

\author{
*Dr. Nirmala M **Uma Devi A.M.
}

\begin{abstract}
:
This is an experimental study based on Campus Recruitment program by various participating companies. The author identifies the challenges faced by companies participating in the campus recruitments and further proposes a new innovative enriched engagement model for campus hiring that addresses these issues. The response of the companies to adopt the new model has been evaluated against factors of innovation and Change Management.
\end{abstract}

This enriched engagement model enables the students to develop, sharpen and have a deeper understanding of the company, job role, placement process, and enhance their skills necessary for the job, be it problem-solving, reasoning and communication abilities.

Through this study campus recruitment policy makers in Indian and Foreign companies' would be more efficient in their attempt to explain, predict and account for factors that impede or facilitate the implementation of the newly proposed enriched engagement campus recruitment model across the country's placement ecosystem.

This study aims at identifying the divide between Indian and Foreign companies in their approach towards Innovation and Change Management which is evaluated by their response towards adopting the new model.

\subsection{Introduction:}

In the present VUCA (Volatile, Uncertain, Complex and Ambiguous) world the Talent Acquisition and Retention function needs to gear up to meet the present business challenges and be prepared to face the future. Organizations are often competing with one another for the same talent, so having a strong talent acquisition system that draws in good people can be a major point of differentiation for employers.

In the present knowledge economy the ability to innovate determines a company's wealth generation capability. Ideas are the bedrock of innovation. Therefore innovation and Change are the key to competitive advantage in highly turbulent environment.

1.2 Research Methodology: This is an experimental study based on proposing a new

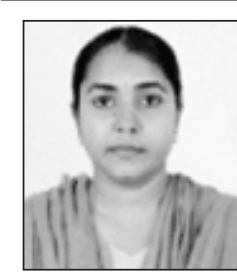

\section{Dr. Nirmala $\mathrm{M}$}

Research Supervisor \& Asst. Professor,

Canara Bank School of Management Studies,

Bangalore University,

Central College Campus, Bangalore

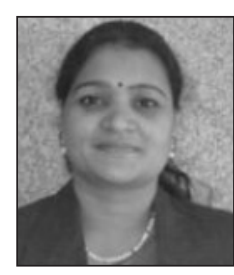

\section{Uma Devi A.M.}

Research Scholar (Ph.D),

Canara Bank School of Management Studies,

Bangalore University,

Central College Campus, Bangalore

Email : uma_am@yahoo.com 
innovative enriched engagement model for campus hiring to various companies and observing the reaction of the companies to either accept and participate, or reject the model and understand the reasons for it. The response of the companies to adopt the new model has been evaluated against factors of innovation and Change Management.

Primary Data is collected by interaction with the companies and participation in the experiment.

Secondary data has been collected from the companies' websites, journals, books and news articles etc.

\section{The Case :}

"India churns out tens of thousands of graduates each year but less than $25 \%$ of them are "employable" or possess the basic skills necessary for any industry role", says a report by NSDC. The sheer number of graduates coming out of universities and colleges is an imposing issue for the companies. However, Campus Hiring is still the most preferred choice for a large number of companies but majority of them concede that it is really hard to attract the best talent.

Oracle CEO, Mark Hurd, in the World Conference on HCM in March 2015, stated that "companies in all industries face the same challenges of having to find talent in the midst of a generational shift. Baby boomers are retiring in droves, while millennial, who by 2020 will represent $50 \%$ of the workforce, are motivated by entirely different factors and have wildly different expectations for the workplace than preceding generations". "They will trade higher pay for greater flexibility". However Companies are disappointed at the dismal selections during Campus Recruitment events and are worried over the ever escalating time and money spent in finding the right talent. The conversions are only $10-15 \%$ of applicants.

The reasons attributed to the low selection from analyzing the feedback from companies that recruit from campuses are:

- Academic Scores not an indication of individual's knowledge

- Lack of basic skills : Communication Skills, Articulation, Data handling Skills, analytical skills etc

- Lack of Soft Skills, Domain Knowledge, Commitment to the job, and understanding Corporate Expectations

- High Dropout Rate even among offered candidates.

Presently the process of campus recruitment is as follows:

\subsection{The Present Campus Recruitment Process}

The companies approach colleges in the prefinal semester, for scheduling the campus drive. The company profile, the eligibility requirements, job profile, job location compensation package and all related information is shared with the colleges for the information of the students. The campus placement process starts with a pre-placement talk.

Many students attend the pre-placement talk without actually doing their background research about the company and job, based on the prior information given to them. So they are unable to take the right decision and often tend to heed to the advice of friends. There is a herd mentality observed among the students, and not an informed decision. So the student is not clear about the nuances of the job and whether the job offered is suitable for the 
student and whether they have the required skills required for the job. This is followed by the selection process, each company having several rounds of selection. Sometimes the final round is held at the company's premises on a deferred date.

Hence the process gets over in one day or is staggered. Some companies offer a Letter of intent to the selected students, while others just submit a consolidated list of selected students to the placement office of the host colleges.

The onboarding and document submission and verification happens once the students have completed the course which is around JuneJuly every year. So there is a gap of almost 5-10 months before the actual onboarding happens. During this period the students attend other campus drives and some get multiple offer letters.

Every year the war of acquiring talent is becoming harder. Companies are doing their best to align to the expectations of the new generation and be relevant to their new changing needs

\subsection{The Present Talent Acquisistion Model:}

\section{Simple Engagement Model (Current)}

The current model, the Simple Engagement Model (SEM) is illustrated below and suffers from the drawbacks already discussed in the background section.

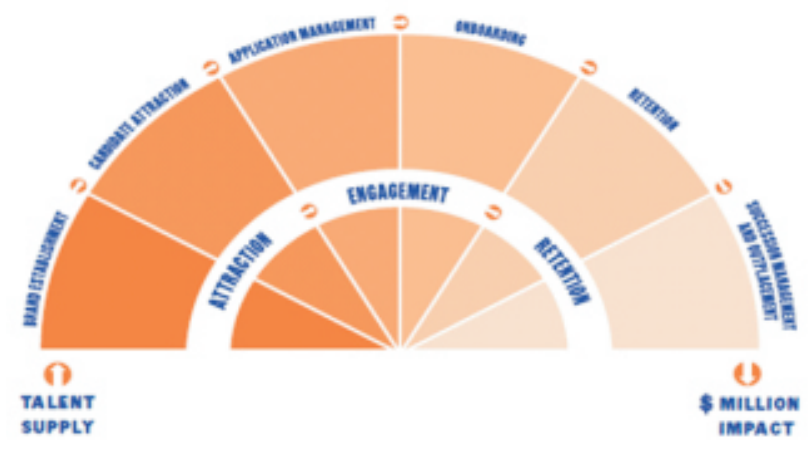

Branding is the major problem as reported by a large number of companies. Apart from the leading companies most others are unable to make their presence felt. Brand Establishment is not effective as corporate presence in nonengineering colleges is very poor. Most often the first interaction happens during preplacement talks. Concerted efforts towards candidate attraction are also during preplacement talk only. Hence students have very less time to explore and know more to make an informed decision.

The second stage, "engagement " starts only with candidate application management, ie. Only when the candidate applies for the job during the campus placement process. Further communication to the selected candidates happens only after course completion and the students get the results. So there is a lull between interview date and time of on boarding. Upon on boarding, companies have induction program lasting 1 day to a week. Here some companies also have buddy system where handholding the selected candidate happens over a short period of time (2-3 months).

The third stage, the Retention Stage involves identifying high performers and makes sure employee engagement efforts are targeted towards them. But it is during the first few months where potential high performers are not identified and this leads a topeople quitting the company.

\subsection{The Problem:}

This leads to various problems for companies like:

1. Replacement

2. Training Costs

3. Time Delay

4. Forecasting 
5. Workforce planning issues all of which are overheads to the companies.

Apart from that, the entire campus recruitment process is lackadaisical from the companies' perspective. There is a dropout of students at the following points:

1. Immediately after the pre-placement talk due to lack of awareness of the company and job roles. This is the most important issue regarding "branding".

2. Some get multiple offers and are not decided about which company they are going to join.

3. Some who get offers aim at higher education and do not join at all

4. Some students are there for an experience not really intending to take up the job if offered.

5. Some join and then drop out within the first one or two months itself as they realize the difficulties of the job or they feel that was not the job for them.

6. Majority of them (about $80-85 \%$ ) do not get shortlisted at all.

From the students' perspective the following major problems have come to light:

1. Job Roles are not properly understood

2. Students do not have any exposure to the industry in terms of internship or in-plant experience.

3. The compensation components are not understood, thus many a time leading to withdrawal after first 2-3 months.

4. Field jobs are the toughest ones as compensations are high, which attract students but the on-field reality is not everyone's cup of tea. Again there is a high dropout in such case.
5. Each industry and sector have their own challenges and competition in the market.

\subsection{The Proposed Model for Campus Recruitment:}

An event was organized to address the concerns of the current model with the support of NHRD Network. To address these and other issues observed among students such as lack of awareness of the opportunities available, skill sets required and career progression, an inclusive and collaborative initiative to bring together all the stakeholders, i.e., the educationists, recruiters, students, training \& development companies, on the same platform to enhance the quality and number of placements through campus recruitment was undertaken. Also a new recruitment model for Campus Hiring was proposed

There were a total of 40 companies participating, from BFSI sector, KPO sector and from Retail sector apart from third party Recruitment firms and training service providers. Companies including, TCS, Concentrix, Infosys, CapGemini, ICICI prudential, MPhasis, ICICI Securities, Exide Life Insurance, Reliance Retail, Indiamart Digital Matics, Ezeone, Indianmoney.com etc.

This event was conducted in an expo format There were three 3 plenary sessions, sector wise with experts from the field discussing the upcoming job requirements, deglamorizing the jobs and skill sets required for these jobs. This was intended to educate the students about opportunities available to them and also help them set their expectations right.

Pool campus drives for all the participating companies were organised in Feb and March 2016, so that students had ample time to skill themselves up, and attend placement talk fully aware of the job requirements. The second session included management games for the 
students like Poster-Making, Product Launch and Jamming session to unleash the creativity and communication skills of the students. This was intended to give an insight to the companies' about the potential of the available talent pool.

Since training companies catering to the skills required from the industry were also available on the same platform, colleges could seek their assistance for training programs.

This event was intended to create synergy among all the stakeholders and make the Campus Placement Exercise more fruitful to all concerned.

A new model for campus Recruitment was proposed to the companies called the

Lean -Talent Value Chain(Lean-TVC) Enriched Engagement Model

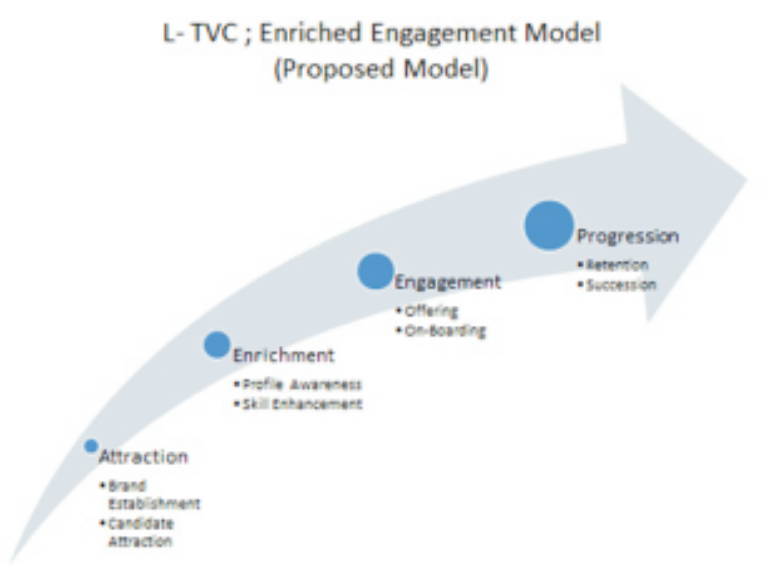

In this model companies need to establish their Corporate Brand by participating in such preplacement events, Management Fests etc.

Many colleges are willing to host such pooled pre-placement events. Candidate Attraction can become part of these events by sponsoring prizes, offering opportunities like shadowing the leader(spending a day with CXOs), internship for students, company visits or some skill development initiatives as a reward based on their performance in management fest- like games and pre-placement events. This will reduce the stress on the students and they will give their best performance since it is in a gamified format. This is an effort to gamify the candidate attraction process.

The second stage of Enrichment happens by creating awareness about the job profiles on offer to the students. Since companies executives are present students can interact with them directly and get clarification. The plenary sessions where industry experts advice the students on the industry requirement, expectation, skills required, and profile awareness, the students are hence well informed about what to look forward to. Students can undertake skill enhancement training relevant to the industry they want to join. There is sufficient time for the students to discuss with company executives and also family and friends before they actually appear for the campus selection process. They also have ample time to undertake the required training. Since these events are brought to the doorstep of institutions, the first and second year students can also become beneficiaries. Skill Enhancement can start at an earlier stage.

The third stage is the Campus Selection which can happen in their final year. Now students appearing for the final placement are already aware and will appear only for the companies offering job profiles they are interested in. Hence Selections are as they are also better equipped due to the insights gained from the pre-placement event. After selections, companies can have continued engagement with the students by offering some online/ offline modules, projects to be undertaken prior to on boarding. This will create a psychological contract in the minds of the students and attrition after joining will also reduce. Job Progression will also be faster. 
This model will reduce time, effort and expenses for the companies and enable the students to make the right choices without much trial and error. This is a win-win for all stakeholders. At every stage there is a value-add for the company, hence the name Lean-Talent Value Chain Model.

This model when proposed to the companies was very well appreciated and had good participation. During the entire process, the response of the companies towards this new and innovative model was observed.

\subsection{Observations:}

No. of Companies Approached

65(37-Indian; 28-Foreign)

No. of Companies participated 40( Indian-23; Foreign - 17)

\begin{tabular}{|c|c|c|c|c|c|c|}
\hline $\begin{array}{l}\text { SI } \\
\text { no }\end{array}$ & Observation & Response & $\begin{array}{l}\text { Indian } \\
\text { Companies }\end{array}$ & Percentage & $\begin{array}{l}\text { Foreign } \\
\text { Companies }\end{array}$ & Percentage \\
\hline \multirow[t]{2}{*}{1} & \multirow{2}{*}{$\begin{array}{l}\text { Adoption of the New } \\
\text { Recruitment Method }\end{array}$} & Yes & 23 & $62.2 \%$ & 17 & $60.7 \%$ \\
\hline & & No & 14 & $37.8 \%$ & 11 & $39.3 \%$ \\
\hline \multirow[t]{3}{*}{2} & \multirow{3}{*}{$\begin{array}{l}\text { Decision } \\
\text { Making/Autonomy }\end{array}$} & High & 5 & $13.5 \%$ & 8 & $28.6 \%$ \\
\hline & & Medium & 18 & $48.6 \%$ & 9 & $32.1 \%$ \\
\hline & & Low & 14 & $37.8 \%$ & 10 & $35.7 \%$ \\
\hline \multirow[t]{2}{*}{3} & \multirow[t]{2}{*}{$\begin{array}{l}\text { Resistance to } \\
\text { Change(Multiple } \\
\text { Negotiations) }\end{array}$} & $\begin{array}{l}\text { High(More than } 3 \\
\text { Rounds of } \\
\text { discussions) }\end{array}$ & 20 & $54.1 \%$ & 11 & $39.3 \%$ \\
\hline & & $\begin{array}{l}\text { Low (1-3 Rounds of } \\
\text { discussions) }\end{array}$ & 17 & $45.9 \%$ & 17 & $60.7 \%$ \\
\hline \multirow[t]{3}{*}{4} & \multirow[t]{3}{*}{ Time to Respond } & $\begin{array}{l}\text { High(more than } 4 \\
\text { weeks) }\end{array}$ & 11 & $29.7 \%$ & 6 & $21.4 \%$ \\
\hline & & Medium(2-3 weeks) & 19 & $51.4 \%$ & 14 & $50.0 \%$ \\
\hline & & Low(one week) & 7 & $18.9 \%$ & 8 & $28.6 \%$ \\
\hline \multirow[t]{3}{*}{5} & \multirow{3}{*}{$\begin{array}{l}\text { Partnering with } \\
\text { stakeholders }\end{array}$} & High & 11 & $29.7 \%$ & 14 & $50.0 \%$ \\
\hline & & Medium & 12 & $32.4 \%$ & 3 & $10.7 \%$ \\
\hline & & Low & 14 & $37.8 \%$ & 11 & $39.3 \%$ \\
\hline
\end{tabular}

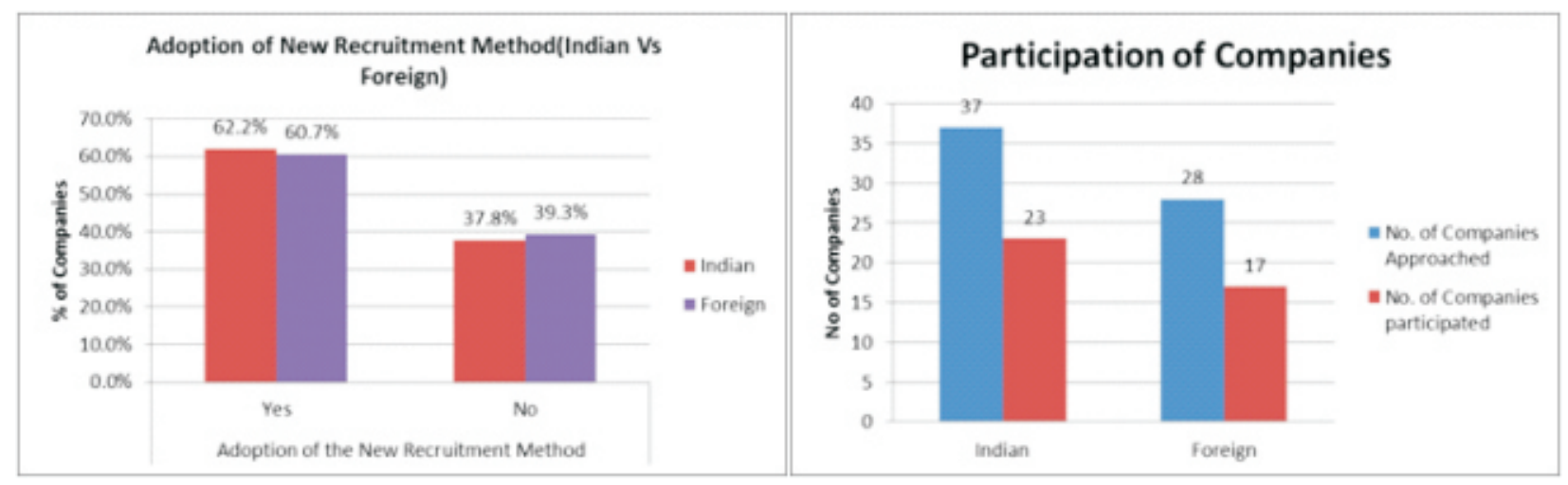




\subsection{Analysis:}

- It can be observed that Adoption of new recruitment method, ie. Openness to Innovative methods of campus recruitment is almost the same in both Indian and Foreign Companies.

- There is higher resistance to change in Indian Companies compared to Foreign Companies. It has taken several rounds of discussion and negotiations with the Indian Companies to convince them to participate.

- Both foreign and Indian companies show similarity in Decision Making or Autonomy. All the companies did require Approvals from their higher Authorities but the number of hierarchical levels in Indian companies is slightly lower than their Foreign Counterparts.

- Time for respond or confirm their participation in this model was higher in Indian Companies while Foreign Companies were quick to respond.

- Partnering with Stakeholders, that is student engagement is higher with foreign companies compared Indian Companies. There have been frequent interactions with the students, in terms of short project assignments, online learning modules, contests and more.
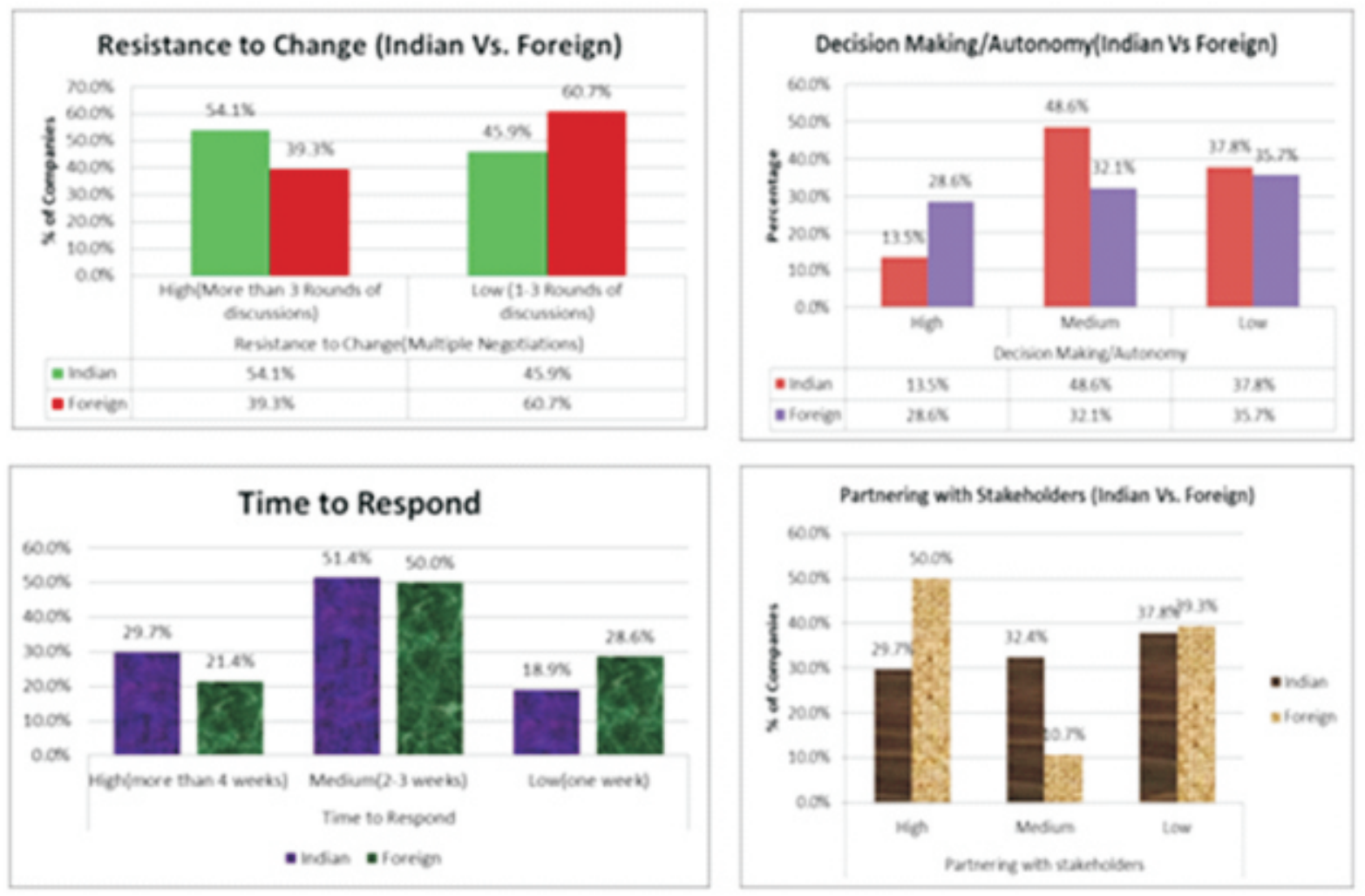

\section{Suggestions and Conclusion}

Campus Recruitment is still the most preferred option for fresher hiring and Volume hiring. $43 \%$ of graduate recruits are from campuses. Cost, time and resources involved in the present model is too high and has to be justified against the candidates hired. This being the case, the proposed model addresses the issues and reduces the budget of campus recruitment to a great extent. 
Further engagement can happen over mobile platform. Chat rooms can be set up where student can be monitored on performance in company initiated discussions. Mobile assessments can also be used to do initial level of screening. Skill Assessments, Behavioral and Aptitude assessments are already available on mobile platform, thereby further reducing the cost of selection to the student as well as companies. Company Executives can also partner as Mentors on this platform

This can become a 360 degree assessment over a period of time, 6 months to a year and Analytics can be used to arrive at employability scores which can be used by companies to shortlist candidates. This will be a better method of assessment unlike the present which test the candidate on one single day.

This will considerably reduce the time for the companies in meeting candidates and yet can get the best talent across campuses.

This experiment has revealed the response of companies to five major areas of Innovation and Change: Adoption of Innovative Ideas, Resistance to Change, Time to respond to change, Decision Making/Autonomy or levels of hierarchy, and extent of partnering with stakeholders. The idea of the innovative method of campus hiring was well received by all the companies but foreign companies seem to be a tad quicker in adopting Innovation and are prepared for Change.

Unless the companies adopt newer ways of recruitment, they may lose out on attracting the best from the campuses which is already suffering from lack of employable graduates.

\section{References:}

A.Somalingam, R.Shanthakumari (2013), Testing and exploring Graduate Employability Skills and Competencies. International Journal of Advancement in Education and social sciences, 1(2), 23-25.
Hema Subramanian (2008), Competencies gap between the education and employability stakes. Journal of management, 5(1), 18-26.

Hum Chan (2013), Exploration of the gap between the business management curriculum and employability requirements. Advances in Asian Social Science, 4(1), 41-53.

Ketan Mulchandani (2011), A study on employability after the management education and its future in India. G lob al Journal of Management 1(2).

Padmini (2012), Education Vs. Employability Gap. Vignana Jyothi Journal of Management, 2(3):pp 28-36.

R. Chaithra (2013), Employability SkillsA study on the perception of the Engineering Students and their Perspective employers. Global Journal of Business and Management Studies, 2(4).

Dhar, Sujay (2012), Employability of management students in India.A I M A Journal of Management and Research, 6(4).

Sanjeev, Agrawal, (2014, Mar 17). How companies can attract the best college talent. Harvard

B u s i n e s s R e vi e w . https://hbr.org/2014/03/how-companiescan-attract-the-best-college-talent

Hickins, Michael, (2015, Mar 26). Oracle Campus Hiring Strategy Is 'Unique'. OracleVoice

F o r b e s. Re tri e ved from http://www.forbes.com/sites/oracle/2015/0 3/26/oracle-campus-hiring-strategy-isunique/\#40a9bda11b10 